\title{
Preparation, characterization and photo activities of Nano-TiO2 thin film
}

\author{
G. $\operatorname{Tian}^{1}$, \& L. N. Zheng ${ }^{1,2^{*}}$, X.Ai ${ }^{1}$, X. R. Jiang ${ }^{1,}$ W. N. Wu ${ }^{3}$ \\ 1 College of Marine Technology and Environmental, Dalian Ocean University,Dalian 116023, \\ China \\ 2 Key Laboratory of Nearshore Marine Environmental Research, Dalian 116023, China \\ Liaoning provincial solid waste management center, Shenyang, 110000, China \\ *8601375@qq.com
}

Keywords: Nano- $\mathrm{TiO}_{2}$ thin film; preparation; test; bactericidal activity

\begin{abstract}
TiO}_{2}$ sol is prepared by sol-gel method, nano- $\mathrm{TiO}_{2}$ thin film on ceramic surface is prepared by dip-coating techniques and is tested by using XRD and AFM, and bactericidal activity of nano- $\mathrm{TiO}_{2}$ thin film is separately studied by Natural fell bacterium experiments and Artificial fell bacterium experiments. The results show that the main type of crystallite for $\mathrm{TiO}_{2}$ is anatase and the crystallite size of $\mathrm{TiO}_{2}$ is $18.98 \mathrm{~nm}$, and the surface shape is fairly uniformity; nano- $\mathrm{TiO}_{2}$ thin film has good ability of bactericidal performance on Escherichia coli, Staphylococcus aureus, Bacillus subtilis and Pseudomonas aeruginosa.
\end{abstract}

\section{Introduction}

$\mathrm{TiO} 2$ is commonly known as titanium white, whose photocatalytic activity is very good, chemical stability is high, to the human body is harmless and the cost is low. It is an ideal inorganic antibacterial agent.

Since 1972 which Fujishima and Hondo found TiO2 sustainable water REDOX reaction in photovoltaic cells, $\mathrm{TiO} 2$ photocatalytic performance has become the research hot spot. After $\mathrm{TiO} 2$ is excited by about 365nm wavelength light, its price bring electronic will be excited to conduction band, form a hole with high oxidation activity and light excited electrons, and generate $\bullet \mathrm{OH}$ and - $\mathrm{O} 2$ reacting with $\mathrm{H} 2 \mathrm{O}$ and $\mathrm{O} 2$. TiO2 thin film has good chemical stability and thermal stability, high catalytic activity, no secondary pollution, without excitant and safe non-toxic characteristics, It can decompose bacteria and contaminants using natural light. It is Long-term benefit for ecological environment. It can be used in light battery electrodes, water decomposition, organic carrier and vessel material, etc.

Currently, it is a development prospect of photoelectric materials, and is one of green environmental protection and bioceramic catalysts. Nano-TiO2 thin film is prepared by using sol-gel method in this paper, Using X-ray diffractometer and atomic force microscope nano-TiO2 thin film on the surface of ceramic tile, characterize XRD and AFM. The bactericidal performance of film is tested through natural drop experiment.

\section{The experiment part}

\section{Preparation of Nano-TiO2 Thin Film}

(1) Preparation of Nano-TiO2 Sol

A certain amount of anhydrous ethanol which was measured was put into the beaker, and the right amount of butyl titanate was slowly added into the beaker solution, then stirring magneticly for $120 \mathrm{~min}$. After mixing, 2\% of the total volume acetyl acetone was added as a chelating agent, then concentrated HNO3 was added, adjusting the $\mathrm{pH}$ of the solution, and then mixing 30 min, finally droping distilled water in the mixture to get the transparent sol solution.

(2) Preparation of Nano-TiO2 Thin Film

Ceramic tile glaze was used as a carrier of load, diping the glazed tile vertical in the sol, Dip- 
pulling method coating, taking out to deliquesce in the air, putting it in $100{ }^{\circ} \mathrm{C}$ constant temperature box for drying and heat preservation, then putting it in the muffle furnace for roasting. After Natural cooling, the nano-TiO2 Thin Film was got. Repeating the above operation, the different thickness nano-TiO2 Thin Films were got.

\section{Characterization of Nano-TiO2 Thin Film}

\section{(1)XRD characterization}

Adopting the Japanese guide tianjin company for BD - 6000 X-ray diffractometer, the ceramic surface of nano-TiO2 thin film was characterized with XRD.

(2) AFM characterization

Adopting the Japan Olympus atomic force microscope, the ceramic surface of nano-TiO2 thin film was characterized with AFM .

Bactericidal performance of Nano-TiO2 Thin Film

\section{Natural bacteria experiment}

The ceramic tile and ceramic tile blank sample (parallel to do three copies) were put indoor and ventilated bad place, keeping natural light irradiation conditions after a certain time (6 h, $24 \mathrm{~h}$ ), Putting it in the destroy bacteria in a petri dish, the sterilized beef extract peptone medium was added, and amount to just cover ceramic tile was added, In the constant temperature of $37{ }^{\circ} \mathrm{C}$ incubator for $24 \mathrm{~h}$, the number of colonies was recorded.

(2) Artificial inoculation experiment

Blank tile and ceramic tile sample were put on super clean bench, using ultraviolet light. Both the front and opposite were sterilized for $20 \mathrm{~min}$. Respectively taking of $0.5 \mathrm{ml}$ bacteria liquid of concentration for $106 \mathrm{cfu} \bullet \mathrm{mL}-1$ to vaccinate in $7.5 \times 4 \mathrm{~cm} 2$ blank samples surface with the ceramic tile ceramic tile and pave, covering its surface using fresh plastic film, irradiating a certain period of time $(1.0 \mathrm{~h} 、 2.0 \mathrm{~h} 、 4.0 \mathrm{~h} 、 8.0 \mathrm{~h} 、 12.0 \mathrm{~h} 、 24.0 \mathrm{~h})$ by $30 \mathrm{~W}$ fluorescent lamp, $45 \mathrm{~cm}$ of Irradiation distance, $37 \pm 1{ }^{\circ} \mathrm{C}$ of experiment temperature, $60 \%$ of relative humidity. $9.5 \mathrm{ml}$ diluent bacterium fluid flush rinsing was used on the surface of the ceramic tile ceramic tile and sampling to sterilization in a petri dish, after mixing, 1: 10 was dilutted, then choosing $1 \sim 2$ suitable bacteria liquid concentration, taking $0.1 \mathrm{ml}$ as colony number to count, Each dilution degrees vaccination three nutrient AGAR medium were put in constant temperature of $37^{\circ} \mathrm{C}$ for $24 \mathrm{~h}$, Calculating the sterilization rate.

(3) The calculation formula of sterilization rate

$\mathrm{a}=(\mathrm{A}-\mathrm{B}) / \mathrm{B} * 100 \%$

in the type :

sterilization rate;

the ceramic tile on the surface of Blank colony count ;

the ceramic tile on the surface of nano- $-\mathrm{TiO} 2$ samples colony count.

\section{The results and discussion}

\section{XRD analysis of Nano-TiO2 Thin Film}

The XRD characterized on the surface of the ceramic tile of Nano -TiO2 thin film. As shown in figure 1: 


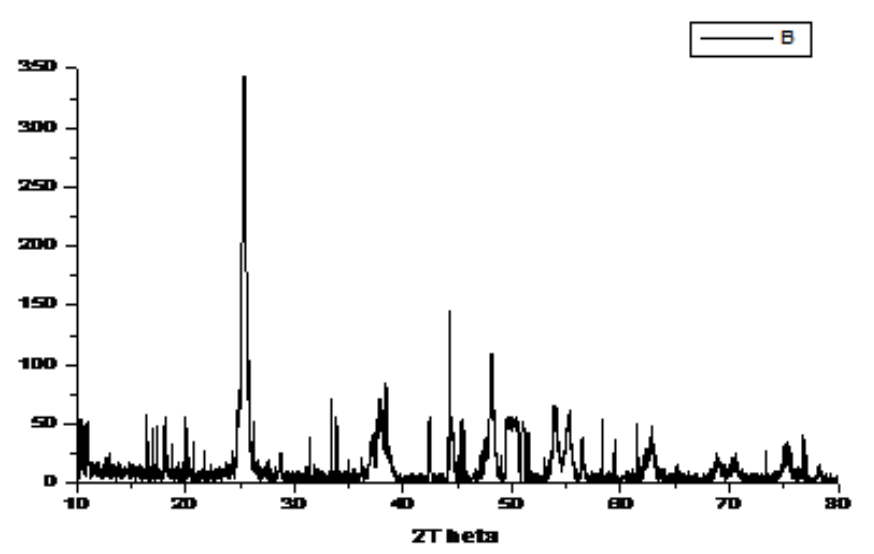

Fig. 1 XRD analysis of $\mathrm{Nano}^{-\mathrm{TiO}_{2}}$ Thin Film

$\mathrm{XRD}$ analysis result was shown that, anatase phase nano-TiO2 was generated in Film, among them, diffraction angle was $2 \theta=25.3583^{\circ}$, Using anatase phase in the theta $2 \theta=25.3583^{\circ}$ diffraction peaks of XRD data, by Scherre formula:

$\mathrm{D}=\mathrm{K} \lambda /(\mathrm{B} \cos \theta)$

$\mathrm{B} 2=\mathrm{BM} 2-\mathrm{BS} 2$

in the type:

D-Grain size;

K-constant , 0.89;

$\lambda$-X wavelength;

$\theta$-Bragg Angle (Half the diffraction Angle );

$\mathrm{B}$-wide $\mathrm{X}$ ray caused by refinement of nanometer particles ;

BM-the measured width is changed;

BS- wide Instrument.

The crystallite size of Nano-TiO2 particles were calculated.,concluding that the particle of $\mathrm{TiO} 2$ was $18.98 \mathrm{~nm}$.

\section{AFM analysis of Nano-TiO2 Thin Film}

The surface of the ceramic tile of nano -TiO2 thin film was characterizated by the AFM. As shown in figure 2:

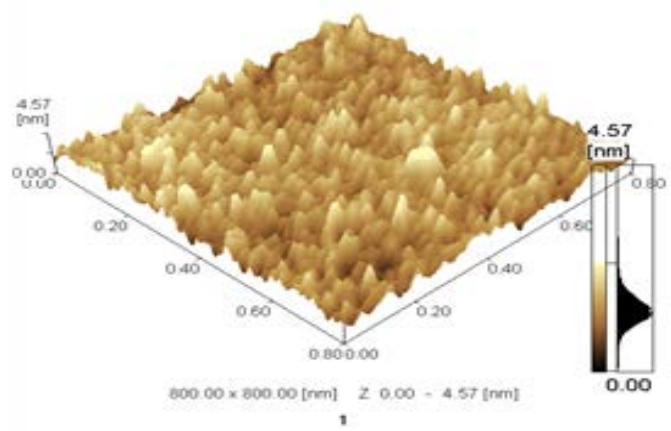

Fig. 2.(a) three dimensional image 


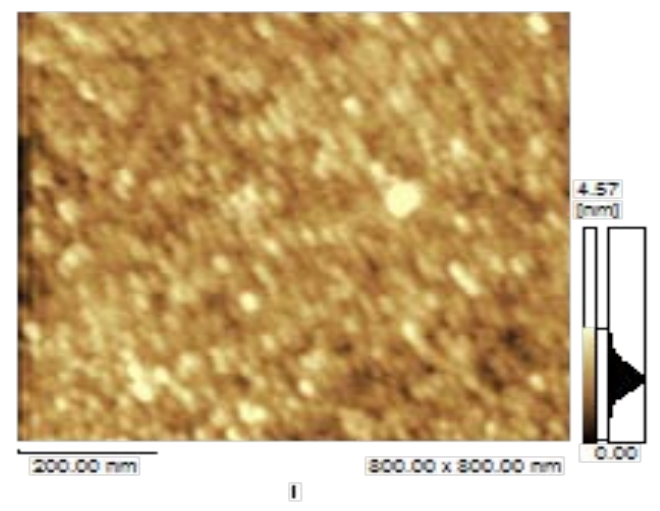

Fig. 2 (b) two dimensional image

AFM analysis result was shown that, the surface of nano-TiO2 thin film was bright and clean, without abnormal big particles, without reunion phenomenon, the particle size of nano-TiO2 thin film was at the nanometer scale, particle size was uniform, The average particle size was $20 \mathrm{~nm}$, The film had a flat organizational structure.

The bactericidal performance of Nano-TiO2 thin film in the natural bacteria experiment

In natural bacteria experiment, the Nano-TiO2 thin film of the Ceramic tile surface was lighted by the irradiation about $6 \mathrm{~h} 、 24 \mathrm{~h}$, the sterilization result was shown in table1:

Table1 Natural bacteria experiment result

\begin{tabular}{l|l|l}
\hline Natura light time [h] & 6 & 24 \\
\hline Colony counts of the blank tile surface [a] & 22 & 67 \\
\hline Colony counts of the sample tile surface [a] & 3 & 6 \\
\hline Sterilization rate [\%] & 86.4 & 91.0 \\
\hline
\end{tabular}

As shown in table1: in the same culture condition, the colony count of the sample ceramic tile surface was less than the blank ceramic tile surface, instructed load Nano-TiO2 thin film Ecological ceramic tile had antiseptic effect, as the growth of the natural light irradiation time, sterilization rate had increased, after natural light irradiation $24 \mathrm{~h}$, sterilization rate had reached to $91.0 \%$. It show that load Nano-TiO2 thin film Ecological ceramic tile had a very good sterilization effect on the natural light irradiation without the strong ultraviolet irradiation.

The bactericidal performance of Nano-TiO2 thin film in the artificial inoculation experiment

In the artificial inoculation experiment, nano-TiO2 thin film of ceramic tile surface was lighted by fluorescent lamp for different time, the sterilizing performance was resulted in Four kinds of the same concentration and different bacteria liquid show as figure 3:

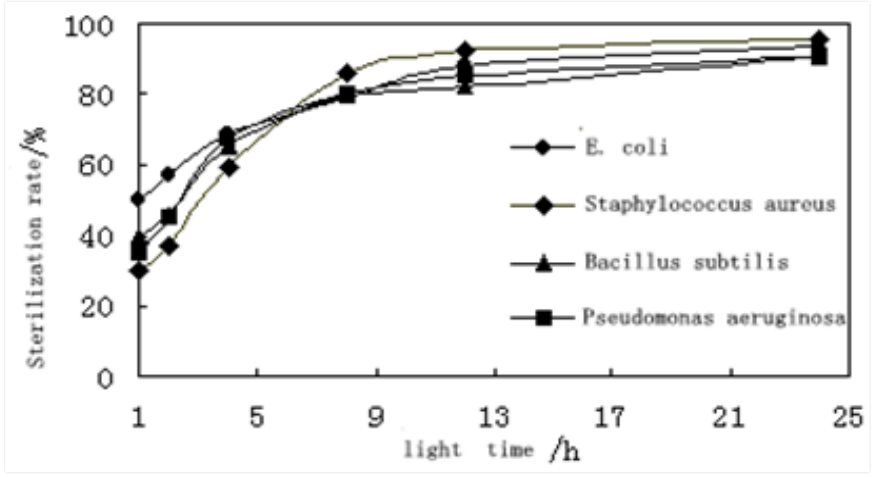

Figure 3 the sterilizing performance of Nano-TiO2 thin film in the same concentration and different bacteria liquid

Figure3 was shown that the sterilizing rate which Nano-TiO2 thin film was to Escherichia coli, staphylococcus aureus, bacillus subtilis, pseudomonas aeruginosa was changed with the changing 
time in the same concentration.

Learning from figure 3, in the light of time of $1 \mathrm{~h}$, membrane of e. coli bactericidal performance was the highest, but as the extension of time, the e. coli sterilization performance increased slowly, its sterilizing rate had reached $93.72 \%$ when the light time of $12 \mathrm{~h}$; the sterilizing rate of bacillus subtilis, pseudomonas aeruginosa reach above $90 \%$ when the light time of $24 \mathrm{~h}$.

So it could be seen that, Nano-TiO2 thin film had good sterilizing performance on e. coli, staphylococcus aureus, bacillus subtilis and pseudomonas aeruginosa .

\section{Conclusion}

Nano-TiO2 thin film which is prepared by sol-gel method show that anatase phase nano-TiO2 is generated in its thin film by using XRD and AFM. Its particle is $18.98 \mathrm{~nm}$, and its size is uniform. Loading nano-TiO2 thin film Ecological ceramic tile can play a very good sterilization effect in the natural light irradiation without the strong ultraviolet irradiation. Nano-TiO2 thin film have good sterilizing performance on e. coli, staphylococcus aureus, bacillus subtilis and pseudomonas aeruginosa .

\section{Acknowledgements}

This research was financially supported by the Liaoning Province Education Science Research Project (L2013275), Liaoning Province Finance Research Foundation (13C019), Liaoning province university student innovation training project(2014) and Dalian Ocean University Students' innovation and entrepreneurship program plan project(2013).

\section{References}

1. Gao. S, Wang. G, Fan. M. D \& Yan.L. 2010. Microemulsion preparation of nanometer $\mathrm{Ti}_{\mathrm{O} 2}$ and its structure characterization [J]. Journal of shenyang chemical university. 24(4): 294-298.

2. Gong B. R, Yao. C \& Chen. Q. 2011,Stearic acid of organic surface modification methods of nano- $\mathrm{TiO}_{2}[\mathrm{~J}]$. Chemical new materials, 39(1):74-78.

3. Jing. X , Wu Y. X \& Chen X. M. 2007. the research progress of nano- $\mathrm{TiO}_{2}$ thin film Preventmist and self-cleaning glass[J]. Zhejiang chemical industry,38(3):8-11.

4. Qiu. S. S, Jiang, C.C \& Hai J. P. 2010. The study on nanometer $\mathrm{TiO}_{2}$ surface modification and its antimicrobial mold performance [J]. The food and fermentation technology, 46(6):5-9.

5. Sheng. G. J, Zhang .Y, Wang. W \& Su Z. H. 2007. Preparation and thermal radiation characteristics research Of nano- $\mathrm{TiO}_{2}[\mathrm{~J}]$.infrared, 28(9):1-4.

6. Sun .Y. G , Xu. Q. L \& Tang B. H . 2010. The preparation and photocatalytic performance of Nano Ni/TiO 2 [J]. Synthetic chemistry, 18(6):705-708.

7. Tang Z. F, Liu P. Y \&Ye. Q. 2003. The preparation and photoinduced super hydrophilic research of $\mathrm{TiO}_{2}$ transparent thin film[J]. Journal of jinan university (natural science edition), 24(1):11-15.

8. Tian S. W, Wang Z. H \& Liu Y. Si. 2006.Preparation and performance study of the $\mathrm{Nano}^{-\mathrm{TiO}_{2}}$ thin film[J]. Materials engineering ,(1):189-192.

9. Xu Q. Y, Wang P \& Zhang J. S. 2004. Preparation and performance characterization of Nano $\mathrm{TiO}_{2}[\mathrm{~J}]$. Coating industry, 34(5):18-21.

10 Zhou. H, GAN X \& Wang J, 2005. Hemoglobin based hydrogen peroxide biosensor tuned by the photovohaic effect of nano titanium dioxide[J]. Ana1.Chem., 77(18):6102-6104. 